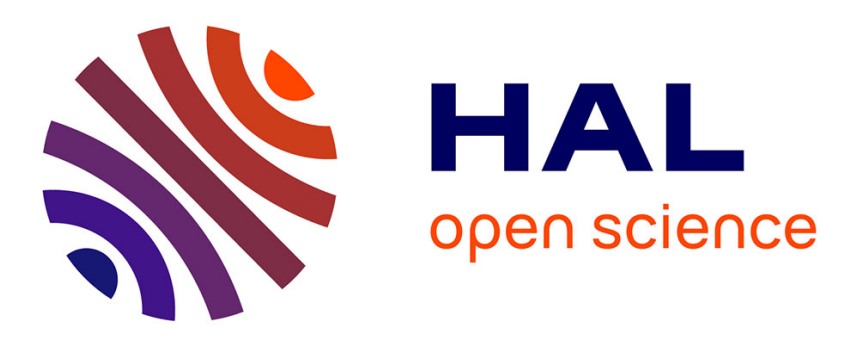

\title{
Dispersal ability of male orchid bees and direct evidence for long-range flights
}

\author{
Tamara Pokorny, Dirk Loose, Gerald Dyker, J. Javier G. Quezada-Euán, \\ Thomas Eltz
}

\section{- To cite this version:}

Tamara Pokorny, Dirk Loose, Gerald Dyker, J. Javier G. Quezada-Euán, Thomas Eltz. Dispersal ability of male orchid bees and direct evidence for long-range flights. Apidologie, 2015, 46 (2), pp.224237. 10.1007/s13592-014-0317-y . hal-01284438

\section{HAL Id: hal-01284438 \\ https://hal.science/hal-01284438}

Submitted on 7 Mar 2016

HAL is a multi-disciplinary open access archive for the deposit and dissemination of scientific research documents, whether they are published or not. The documents may come from teaching and research institutions in France or abroad, or from public or private research centers.
L'archive ouverte pluridisciplinaire HAL, est destinée au dépôt et à la diffusion de documents scientifiques de niveau recherche, publiés ou non, émanant des établissements d'enseignement et de recherche français ou étrangers, des laboratoires publics ou privés. 


\title{
Dispersal ability of male orchid bees and direct evidence for long-range flights
}

\author{
Tamara PoKorny ${ }^{1}$, Dirk Loose ${ }^{2}$, Gerald DyKER ${ }^{2}$, J. Javier G. QueZADA-EuÁN ${ }^{3}$, \\ Thomas ELtz ${ }^{1}$ \\ ${ }^{1}$ Department of Animal Ecology, Evolution and Biodiversity, Ruhr University Bochum, 44780, Bochum, Germany \\ ${ }^{2}$ Department of Organic Chemistry, Ruhr University Bochum, 44780, Bochum, Germany \\ ${ }^{3}$ Departamento de Apicultura, Universidad Autónoma de Yucatán, Mérida, Yucatán 97100, Mexico
}

Received 10 April 2014 - Revised 28 July 2014 - Accepted 10 September 2014

\begin{abstract}
Male Neotropical orchid bees collect volatile chemicals from various sources in the environment in order to compose their characteristic perfume bouquets. Amongst other plants, over 600 species of orchids are exclusively pollinated by the bees during their quest for volatiles. Since the plants usually have a scattered distribution, it is assumed that orchid bees can transport the pollinaria across several kilometres due to their flight capabilities and a high dispersal potential. Until now, very long-range flight distances (up to $45 \mathrm{~km}$ ) of male orchid bees have only been indirectly inferred from habitat requirements of orchids whose pollinaria were carried by captured males, whereas the distances established by direct measures (mark and recapture, radio telemetry) only span distances of up to around $6 \mathrm{~km}$. The discrepancy between inferred and proven distances led us to readdress the question of dispersal ability of male orchid bees. In this study, we used tag, scratch and chemical marking of large numbers of bees to clarify two aspects: (1) the effect of moderate natural obstacles on dispersal and (2) the possibility of very long-range movements across a terrain lacking such obstacles. Our results suggest that a moderate natural obstacle (a valley separating opposite ridges) does not restrain orchid bee movements. Individual bees achieved extraordinary flight distances of more than $50 \mathrm{~km}$ across even terrain, extending the directly proven flight distances of male bees by more than an order of magnitude.
\end{abstract}

\section{Euglossini / orchid pollination / long distance dispersal / gene flow / population genetics}

\section{INTRODUCTION}

Males of the Neotropical orchid bees (Euglossini, Apidae, Hymenoptera) collect volatiles from a number of floral as well as non-floral sources in their environment (Vogel 1966; Dressler 1982; Whitten et al. 1993; Roubik and Hanson 2004; Cappellari and Harter-Marques 2010) and accumulate them in their specialized

Electronic supplementary material The online version of this article (doi:10.1007/s13592-014-0317-y) contains supplementary material, which is available to authorized users.

Corresponding author: T. Pokorny, tamara.pokorny@ruhr-uni-bochum.de Manuscript editor: James Nieh hind leg tibiae. The resulting mixtures eventually constitute species specific perfumes which are emitted during territorial display behaviour, serving as pheromone analogues (Eltz et al. 2005; Zimmermann et al. 2009). Many Neotropical plant species produce floral fragrances attractive to orchid bees, which pollinate the plants during the process of collecting the volatiles. This had been named the male euglossine pollination syndrome (Dressler 1968). Amongst other plants, more than 600 species of orchids depend solely on male orchid bees for pollination (Dressler 1982; Williams and Whitten 1983).

These orchids, like many plants in tropical rainforests, have a scattered distribution (Dodson, unpublished data, cited in Williams and Dodson 1972) which, according to Williams and Dodson 
(1972), would not be explainable if the pollinators were to have short flight ranges, since the effective population size depends on the distances traversed by their pollinators (see also Ackerman 1986). It has often been noted that orchid bees are strong flyers, and individual bees have been sighted over open water as far as $2.5 \mathrm{~km}$ from the nearest land (female bees, Janzen 1971), or at altitudes as much as $1000 \mathrm{~m}$ above their normal foraging locations (see Roubik and Hanson 2004). Individual males carrying orchid pollinaria have been observed at a distance of $45 \mathrm{~km}$ to the nearest known habitat suitable for the respective orchids (Dressler 1982), and it had been speculated that the male bees should be able to cross a distance of $40 \mathrm{~km}$ within a few days, while distances of 80-90 km might be within their range given about a week (Williams and Dodson 1972). Direct evidence for flight capacity obtained via mark and recapture experiments revealed traversed distances of 4 to $6 \mathrm{~km}$ (Ackerman et al. 1982; Raw 1989), while males of the genera Eulaema and Euglossa have been shown to cross open pasture between forest fragments (distances spanning up to $1700 \mathrm{~m}$ ), with steep hills not preventing them from locating and visiting fragrance sources on the far side (Tonhasca et al. 2003). However, Kroodsma (1975) reported that marked Euglossa imperialis were recaptured in successively lower numbers than those obtained at the marking location when baiting the bees at a distance of a 5- and a 10min walk, respectively, while Eltz et al. (1999) recaptured marked Eulaema meriana and Euglossa cognata at the same site after up to 44 days. The two latter studies rather suggest a degree of site fidelity. This seems to be supported by the results of monitoring individual male Exaerete frontalis equipped with small transmitters through radio telemetry over the course of a few days, which revealed that they generally remained within a home range covering an estimated average size of $45 \pm 40$ ha. Nevertheless, one individual was tracked at about $5 \mathrm{~km}$ distance to its core area (Wikelski et al. 2010). The discrepancy of an order of magnitude between proven travelling distances and inferred dispersal potential emphasizes the need for further investigation.
The aim of this study was to address this point using mark and recapture techniques. Various marking procedures had been used to date, including wing notches (Janzen 1971), paint application (Kroodsma 1975; Tonhasca et al. 2003) and marking tags glued on the thorax of larger bees (Eltz et al. 1999). All of these procedures can entail certain setbacks. Wing notches might be obscured by subsequent wing wear and require a long handling time due to the need of a magnifying glass to correctly set and identify the marks. Paint markers, even when applied to body parts not reached by the bees' vigorous grooming (Kimsey 1984), become less visible over time (see Tonhasca et al. 2003; T. Eltz, T. Pokorny pers. obs.), while marking tags, due to their size, have the setback of not being suited for very small species. Therefore, we decided to employ novel marking techniques, chemical marking and scratch marks (see "Methods and materials"), in addition to conventional marking tags. We focused on two aspects of the dispersal ability of male orchid bees, (1) the influence of moderate natural obstacles on their movements and (2) very long range movements across terrain lacking such obstacles. Additionally, we noted the times until recapture in order to gain information on site fidelity and possible travelling times.

\section{METHODS AND MATERIALS}

\subsection{Baiting}

Orchid bee males can be lured to a number of synthetic volatile chemicals, which therefore are used to equip baits (Dodson et al. 1969; Roubik and Hanson 2004). Baits consisted of scent-free tissue paper treated with a standardized amount of chemical compound. Treated tissue paper was separately enclosed in stainless steel mesh tea balls to prevent the bees from direct access to the bait chemicals. Replenishing of baits with the respective compound served to compensate for evaporation, and was applied at half-time for baiting durations lasting longer than $2 \mathrm{~h}$ straight. Baiting was used to attract orchid bees in both experimental setups of this study. 


\subsection{Marking procedures}

Tag marks Opalith bee tags (Graze, Endersbach, Germany) were attached to the bees' thorax using cyanoacrylate glue. The tags are available numbered from 1 to 99 in a variety of colours, allowing individual marking of medium to large bees.

Scratch marks Scratch marks consisted of symbols made up of various combinations of lines which were carefully applied on the thorax of metallic coloured Euglossa bees using a blunted scalpel blade, leaving the scratched areas blackened. This type of marking procedure had been previously tested on caged bees, indicating no negative consequences for the marked individuals, which would retain the marking virtually unchanged over the course of their long lives (up to 6 months under cage conditions, T. Pokorny, unpublished data).

Chemical markers The chemical compounds collected by orchid bees are stored in specialized pockets in their hind tibiae and are retained therein over long periods of time (Eltz et al. 1999). If the bees could be enticed to collect characteristic, not naturally occurring compounds, they would 'mark themselves' in the process. Such compounds could then be identified during successive chemical analysis of the hind leg bouquets. We employed two types of chemical markers, (a) a deuterated version of a common baiting compound, deuterated p-dimethoxybenzene (see Electronic Supplementary Material 1) and (b) a non-volatile compound which does not naturally occur in orchid bee perfume bouquets, cholesterol. Cholesterol was dissolved in either ethanol with p-dimethoxybenzene or in eugenol, two compounds often used to bait male orchid bees, while deuterated $\mathrm{p}$-dimethoxybenzene was attractive on its own. For both markers, previous experiments had indicated that they were attractive to the bees, and that the bees' collecting behaviour was in no way altered. Chemical analyses of the resulting hind leg bouquets revealed the presence of the marking substances (see Electronic Supplementary Material 2).

\subsection{Natural obstacle}

A natural obstacle is a landscape structure hampering or preventing bee movements across it, like large bodies of water, hills or valleys. The influence of a potential natural obstacle on orchid bee dispersal was conducted from March to May 2013 in the forest adjoining the La Gamba research station, Piedras Blancas Reserve, Puntarenas, Costa Rica. Study sites lay on a ridge forming a wide ' $\mathrm{V}$ ' shape, with the opposite sides rising over $100 \mathrm{~m}$ higher than the valley in between. A trail passes along most of the ridge. On each of the two opposite sides of the ridge, two sites along the trail were chosen for their overall suitability (position high on the ridge, surrounding vegetation not too dense). Distances between sites on the same side were 396 (F1-F2) and $590 \mathrm{~m}$ (N1-N2), while opposite sites lay 560 (F2-N2) to $676 \mathrm{~m}(\mathrm{~F} 1-\mathrm{N} 1)$ apart, with the shortest diagonal spanning $753 \mathrm{~m}$, and the longest $810 \mathrm{~m}$ (Figure 1). Six synthetic chemical compounds (1,8-cineole, eugenol, methyl salicylate, p-dimethoxybenzene, methyl cinnamate and vanillin), known to be good attractants for many orchid bee species (Ackerman 1989; Roubik and Hanson 2004), were used to attract bees at the four sites. The sites were always visited for baiting on consecutive days in random order by the experimenters (three people for the first census of each of the sites, thereafter always by one experimenter). Such four-day baiting units were repeated a total of five times. Baiting lasted for $3 \mathrm{~h}$ between 0730 and $1200 \mathrm{~h}$, and baits were replenished after $1.5 \mathrm{~h}$. Bees attracted to the baits were captured with hand nets and marked with either individual tag marks (E. imperialis, Euglossa flammea, and all bees of the genera Eulaema, Exaerete and Eufriesea) or scratch marks (all other species of Euglossa). Scratch marks were specific for each site and repetition, with recaptured bees receiving an additional specific mark. All bees were released after the shortest possible handling time. When a bee was recaptured on the same day on which it had been marked, no additional markings were applied, and it was not noted as recapture.

\subsection{Long-range movements}

Transect experiments to evaluate possible flight distances were conducted during October 2011 and April 2012 on the Yucatán peninsula, Mexico. Transect sites were chosen for large scale habitat suitability, that is, predominantly woody vegetation along the entire transect with no interruptions by larger settlements or agricultural areas. The first site, 'A', was located near Xmatkuil, south of Mérida. Other sites (B-F) along the transect towards the south were 


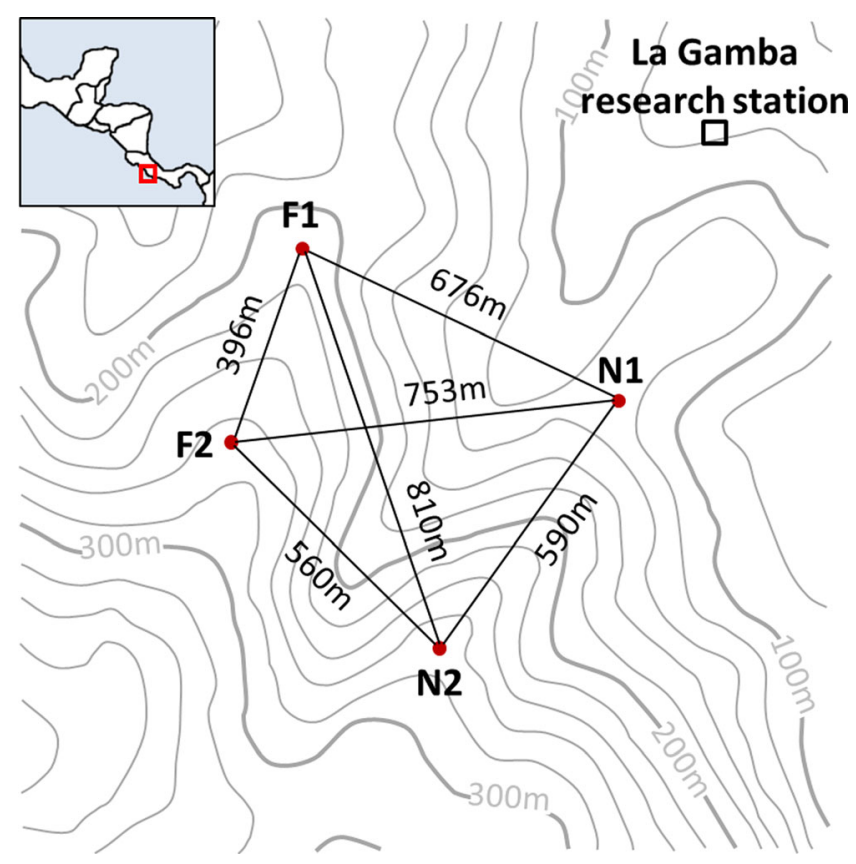

Figure 1. Baiting sites near La Gamba Field Station (N $8^{\circ} 42^{\prime \prime} 61^{\prime}$, W 83 12' 97"), Piedras Blancas Reserve, Puntarenas, Costa Rica with distances between sites (black) and contour lines (grey).

located at distances of approximately 2.5, 5, 10, 25 and $50 \mathrm{~km}$ to site A (Figure 2). The transect line was not entirely straight due to inaccessibility of some areas. We focused on the sibling species Euglossa dilemma and Euglossa viridissima, as they are the most abundant orchid bees of the northern Yucatán peninsula, and can easily be lured to six synthetic chemical compounds (benzyl benzoate, 1,8-cineole, eugenol, methyl salicylate, p-dimethoxybenzene and methyl cinnamate; see Skov and Wiley 2005; Eltz et al. 2008; Pokorny et al. 2013). Chemical marking and scratch marks were employed to mark bees. For chemical marking, which took place only at site A, three large pieces of thick filter paper were saturated with one of the chemical markers each (deuterated pdimethoxybenzene or cholesterol mixed with either eugenol or p-dimethoxybenzene) and were attached to tree trunks in a height of 1.5 to $2 \mathrm{~m}$. The three marker baits were exposed simultaneously and with distances of $>100 \mathrm{~m}$ between each other. The compounds were replenished daily while the filter papers were still slightly fragrant. Therefore, the chemicals were accessible to the bees around the clock. Unlike chemical marking, scratch marks were applied at every transect site, with different scratch marks for each site (Figure 2). For each repetition, another specific mark on the bees' scutellum was added to the basic site mark, leading to specific mark combinations for each site and repetition. To routinely mark and recapture bees at the transect sites over the following days, at least two and up to six different baits were exposed simultaneously at the current baiting site, hung from vegetation at a height of 1.5 to $2 \mathrm{~m}$ with distances of 1.5 to $2.5 \mathrm{~m}$ between adjoining baits. The number of compounds (two to six) used to attract bees was raised during the course of the experiment in order to counteract a potential loss of attractiveness due to repeated exposition of each single compound (see Eltz et al. 2005; Pokorny et al. 2013). Baiting was conducted between 0745 and $1300 \mathrm{~h}$. Sampling duration at the transect sites and the number of sites sampled per day differed for the two seasons due to weather conditions. Rainfall and lower temperatures (as common in the end of the rainy season) often result in low numbers or a total lack of bees (T. Pokorny, pers. obs., and see Ackerman 1983 on seasonal abundance), with prolonged baiting duration not yielding significantly higher numbers of bees. In the rainy season (October), transect sites were therefore sampled more often 


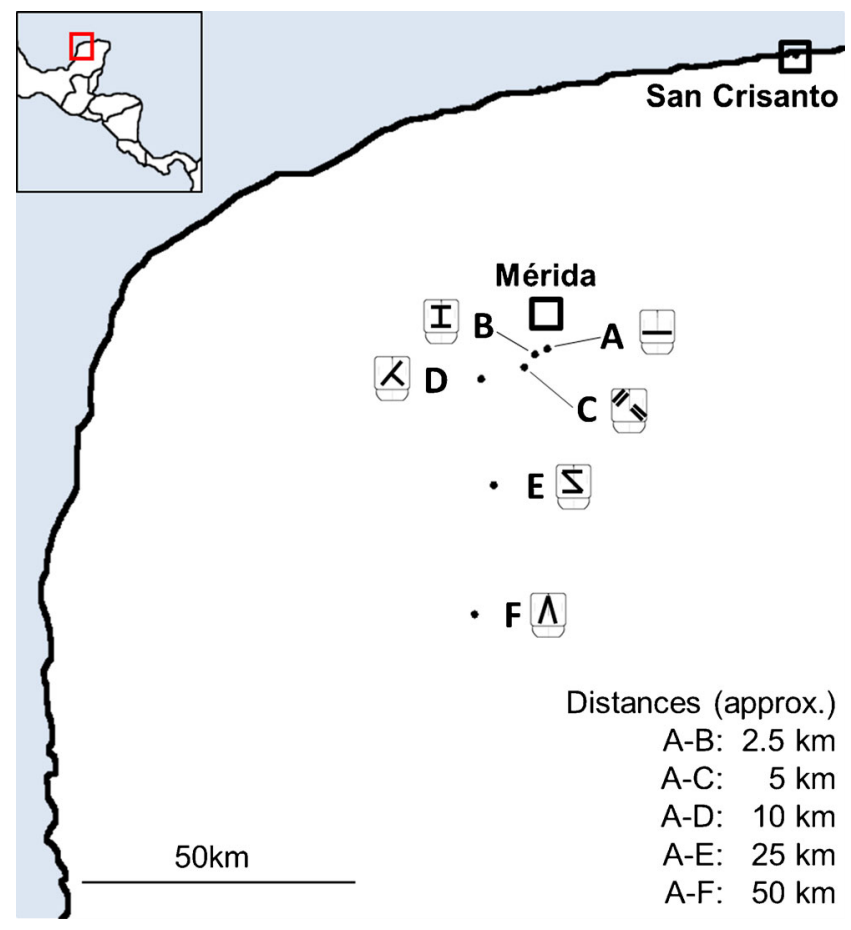

Figure 2. Transect sites on the Yucatán peninsula, Mexico. Sites could not be positioned on a straight line due to inaccessibility of the required areas. Specific scratch marks for each site and their position on the bees' thorax pictured next to the respective site.

(five repetitions per site) but for shorter durations (65-75 min per sampling, three sites a day) than in the dry season (April, three repetitions of $4 \mathrm{~h}$ per site and therefore only one site a day). Sites were visited in random order, though always all six sites were visited before another round of repetitions was begun. In the dry season, when baiting duration was $4 \mathrm{~h}$, baits were replenished after $2 \mathrm{~h}$ to compensate for evaporation.

Bees were captured from baits in regular intervals by two experimenters using hand nets and furnished with the specific scratch mark for each site and repetition. Thereafter, if the bee had been captured for the first time (no previous scratch mark present), each hind leg pouch was gently squeezed in order to try to expel the stored perfume liquid. If a droplet emerged, it was taken up on a clean piece of filter paper. The bee was then released, and the filter paper was immediately placed in a vial containing $500 \mu \mathrm{l}$ of hexane, sealed and, after return to the lab, stored at $-20{ }^{\circ} \mathrm{C}$ until chemical analysis in Bochum, Germany.

\subsection{Chemical analyses}

Extracts of hind leg bouquet were analyzed using coupled gas chromatography and mass spectrometry (GC-MS). Injection was splitless on a DB-5 column ( $30 \mathrm{~m}, 0.25 \mu \mathrm{m}$ film thickness, $0.25 \mathrm{~mm}$ diameter), and the oven of the HP5890II GC was programmed from 60 to $300{ }^{\circ} \mathrm{C}$ at $10^{\circ}$ per min with additional 15 min at $300{ }^{\circ} \mathrm{C}$. A HP5972 MS served as detector. Extracts were scanned for the presence of the chemical markers. Compound identification was accomplished by comparison of retention index and mass spectrum of the candidate compounds with those of previously analyzed aliquots of the chemical markers.

\subsection{Statistical analyses}

Exact binomial tests and Spearman rank correlation were conducted for analyses on distribution patterns and parameter correlations using R v.3.0.2 (R Core Team 2013). 


\section{RESULTS}

\subsection{Natural obstacles}

A total of 2262 bees were marked (695 Opalith tags, 1567 scratch marks). Sixty-three marked individuals were recaptured (42 with Opalith tags, 21 with scratch marks, same-day-recaptures excluded, see Table I). The highest rate of recaptures, $8.7 \%$, was noted for E. imperialis (32 of 368), the second highest rate for E. flammea ( 9 of 179). Of all species in which a minimum of 60 individuals had been marked, at least one marked individual was recaptured, though the most abundant species (Euglossa dodsoni, 575 marked individuals) yielded a recapture rate of only $1 \%$. Three individuals of E. imperialis were recaptured twice. We included only the flights until first recapture in the statistical analyses.

Eighteen bees were recaptured at the same site at which they had been marked, while 19 had changed position within one side of the ridge and 26 were recaptured at sites on the opposite side of the ridge (see Table I, Figure 3). There was no higher probability of a bee being recaptured at the same site at which it had been marked than that of it being recaptured at any of the other three sites (exact binomial test, $n 1=18, n 2=45$, expected ratio $0.25, P=0.56$ ). Also, the numbers of bees remaining on the same side of the ridge (37 individuals) did not significantly differ from those being recaptured on the opposite side (26 bees, exact binomial test, $n 1=37, n 2=26$, expected ratio $0.5, P=0.21)$. All but one $(\mathrm{N} 2->\mathrm{F} 1)$ of the 12 possible flight vectors between sites were documented for at least one individual (Figure 3), and there were no predominant combinations of sites (mark to recapture). Of the three E. imperialis recaptured twice, one was always recaptured at the same site at which it had been marked (N2), while the two others had moved between sites: N1->F1->N2 and N1->F1->F2.

Time until recapture varied (1 to 42 days, Table I), and there was a negative correlation between time until recapture and the distance between marking- and recapture-site (Spearman rank correlation, $R=-0.45, P<0.01$, Figure 4), with half of those bees recaptured after more than 10 days being recaptured at the same site at which they had been marked (Figure 4). The maximal timespan between marking and resighting was beyond the timeframe of the experimental observations and was 49 days for one individual E. meriana.

\subsection{Long-range movements}

Overall, we obtained 1203 samples of individual perfume loads (818 of E. dilemma, 385 of E. viridissima) for GC/MS analysis of chemical markers, though on average less than every second E. dilemma and every third E. viridissima yielded a droplet of perfume liquid upon squeezing their hind tibial pouches. Recaptures were predominantly from the same site at which the bees had been marked: in total 57 with scratch marks (47 E. dilemma, ten E. viridissima) and 16 with chemical markers (six E. dilemma, ten E. viridissima). Of the bees which had been recaptured at a different site, three had traversed a distance of about $2.5 \mathrm{~km}$ (two E. dilemma, one E. viridissima, Figure 5). One E. dilemma was recaptured at site $\mathrm{C}(5 \mathrm{~km}$ distance to the chemical marking site, A) carrying cholesterol in its hindleg bouquet. No recaptures were noted for distances of 10 and $25 \mathrm{~km}$. The longest traversed distances were $45 \mathrm{~km}$ by a scratch-marked E. viridissima, recaptured 2 days after marking, and $50 \mathrm{~km}$ by an individual of E. dilemma captured at site $\mathrm{F}$ with cholesterol present in its hind leg bouquet (Figure 5). Time until recapture could be evaluated for bees bearing scratch marks, and lay between 1 and 17 days. After conclusion of the experiment in spring 2012, two further long-range movements of marked bees were observed: other baiting experiments conducted at San Crisanto, a coastal village $70 \mathrm{~km}$ northeast of site A, resulted in the capture of one E. viridissima (Figure 6a) 14 days after it had originally been scratch-marked at site B, leading to a traversed distance of $72 \mathrm{~km}$, while the other bee (also E. viridissima, Figure 6b) was recaptured 12 days after scratch marking at site E, having flown an astonishing distance of $95 \mathrm{~km}$.

\section{DISCUSSION}

Male orchid bees are considered to be strong flyers, and as they are supposed not to be bound to a specific site (as females are to their nest) until 
Table I. List of bees recaptured during the natural obstacle experiment with details on the recorded parameters.

\begin{tabular}{|c|c|c|c|c|c|c|}
\hline Marked & Recaptured & Species & Marker & $\begin{array}{l}\text { Site marked-> } \\
\text { Recaptured }\end{array}$ & $\begin{array}{l}\text { Distance } \\
\text { flown (m) }\end{array}$ & $\begin{array}{l}\text { Days until } \\
\text { recapture }\end{array}$ \\
\hline 21.03 .2013 & 23.03 .2013 & E. imperialis & Tag & $\mathrm{N} 1->\mathrm{N} 2$ & 590 & 2 \\
\hline 21.03 .2013 & 22.03 .2013 & E. imperialis & Tag & $\mathrm{N} 1->\mathrm{F} 1$ & 676 & 1 \\
\hline 21.03 .2013 & 29.03 .2013 & E. imperialis & Tag & $\mathrm{N} 1->\mathrm{F} 2$ & 753 & 8 \\
\hline 21.03 .2013 & 25.03 .2013 & E. tridentata & Scratch & $\mathrm{N} 1->\mathrm{F} 2$ & 753 & 3 \\
\hline 22.03 .2013 & 29.03 .2013 & E. flammea & Tag & $\mathrm{F} 1->\mathrm{F} 2$ & 396 & 7 \\
\hline 22.03 .2013 & 11.04 .2013 & E. flammea & Tag & $\mathrm{F} 1->\mathrm{F} 2$ & 396 & 20 \\
\hline 22.03 .2013 & 29.03 .2013 & E. imperialis & Tag & $\mathrm{F} 1->\mathrm{F} 2$ & 396 & 7 \\
\hline 22.03 .2013 & 29.03 .2013 & E. imperialis & Tag & $\mathrm{F} 1->\mathrm{F} 2$ & 396 & 7 \\
\hline 22.03 .2013 & 25.03 .2013 & E. sapphirina & Scratch & $\mathrm{F} 1->\mathrm{F} 2$ & 396 & 3 \\
\hline 22.03 .2013 & 23.03 .2013 & E. dodsoni & Scratch & $\mathrm{F} 1->\mathrm{N} 2$ & 810 & 1 \\
\hline 22.03 .2013 & 30.03 .2013 & E. sapphirina & Scratch & $\mathrm{F} 1->\mathrm{N} 2$ & 810 & 8 \\
\hline 23.03 .2013 & 24.04 .2013 & E. gorgonensis & Scratch & $\mathrm{N} 2->\mathrm{N} 2$ & 0 & 1 \\
\hline 23.03 .2013 & 26.03 .2013 & E. imperialis & Tag & $\mathrm{N} 2->\mathrm{N} 2$ & 0 & 3 \\
\hline 23.03 .2013 & 24.04 .2013 & E. imperialis & Tag & $\mathrm{N} 2->\mathrm{N} 2$ & 0 & 1 \\
\hline 23.03 .2013 & 26.03 .2013 & E. tridentata & Scratch & $\mathrm{N} 2->\mathrm{N} 2$ & 0 & 3 \\
\hline 23.03 .2013 & 25.03 .2013 & E. dodsoni & Scratch & $\mathrm{N} 2->\mathrm{F} 2$ & 560 & 2 \\
\hline 23.03 .2013 & 29.03 .2013 & E. imperialis & Tag & $\mathrm{N} 2->\mathrm{F} 2$ & 560 & 6 \\
\hline 23.03 .2013 & 29.03 .2013 & E. imperialis & Tag & $\mathrm{N} 2->\mathrm{F} 2$ & 560 & 6 \\
\hline 23.03 .2013 & 29.03 .2013 & E. cingulata & Tag & $\mathrm{N} 2->\mathrm{F} 2$ & 560 & 6 \\
\hline 25.03 .2013 & 29.03 .2013 & E. championi & Scratch & $\mathrm{F} 2->\mathrm{F} 2$ & 0 & 4 \\
\hline 25.03 .2013 & 27.04 .2013 & E. imperialis & Tag & $\mathrm{F} 2->\mathrm{F} 2$ & 0 & 2 \\
\hline 25.03 .2013 & 11.04 .2013 & E. imperialis & Tag & $\mathrm{F} 2->\mathrm{F} 2$ & 0 & 17 \\
\hline 25.03 .2013 & 26.03 .2013 & E. imperialis & Tag & $\mathrm{F} 2->\mathrm{N} 2$ & 560 & 1 \\
\hline 26.03 .2013 & 07.05 .2013 & E. dodsoni & Scratch & $\mathrm{N} 2->\mathrm{N} 2$ & 0 & 42 \\
\hline 26.03 .2013 & 11.04 .2013 & E. dodsoni & Scratch & $\mathrm{N} 2->\mathrm{F} 2$ & 560 & 16 \\
\hline 26.03 .2013 & 29.03 .2013 & E. flammea & Tag & $\mathrm{N} 2->\mathrm{F} 2$ & 560 & 3 \\
\hline 26.03 .2013 & 29.03 .2013 & E. tridentata & Scratch & $\mathrm{N} 2->\mathrm{F} 2$ & 560 & 3 \\
\hline 27.03 .2013 & 06.05 .2013 & E. dodsoni & Scratch & $\mathrm{F} 1->\mathrm{F} 1$ & 0 & 40 \\
\hline 27.03 .2013 & 11.04 .2013 & E. flammea & Tag & $\mathrm{F} 1->\mathrm{F} 2$ & 396 & 15 \\
\hline 27.03 .2013 & 28.03 .2013 & E. villosiventris & Scratch & $\mathrm{F} 1->\mathrm{N} 1$ & 676 & 1 \\
\hline 28.03 .2013 & 22.04 .2013 & E. imperialis & Tag & $\mathrm{N} 1->\mathrm{N} 1$ & 0 & 25 \\
\hline 28.03 .2013 & 08.04 .2013 & E. tridentata & Scratch & $\mathrm{N} 1->\mathrm{N} 1$ & 0 & 11 \\
\hline 29.03 .2013 & 30.03 .2013 & E. dodsoni & Scratch & $\mathrm{F} 2->\mathrm{N} 2$ & 560 & 1 \\
\hline 29.03 .2013 & 22.04 .2013 & E. erythrochlora & Scratch & $\mathrm{F} 2->\mathrm{N} 1$ & 753 & 24 \\
\hline 31.03 .2013 & 06.05 .2013 & E. gorgonensis & Scratch & $\mathrm{F} 1->\mathrm{F} 1$ & 0 & 36 \\
\hline 08.04 .2013 & 22.04 .2013 & E. imperialis & Tag & $\mathrm{N} 1->\mathrm{N} 1$ & 0 & 14 \\
\hline 08.04 .2013 & 22.04 .2013 & E. imperialis & Tag & $\mathrm{N} 1->\mathrm{N} 1$ & 0 & 14 \\
\hline 08.04 .2013 & 23.04 .2013 & E. imperialis & Tag & $\mathrm{N} 1->\mathrm{F} 1$ & 676 & 15 \\
\hline 11.04 .2013 & 04.05 .2013 & E. imperialis & Tag & $\mathrm{F} 2->\mathrm{F} 2$ & 0 & 23 \\
\hline 11.04 .2013 & 06.05 .2013 & E. flammea & Tag & $\mathrm{F} 2->\mathrm{F} 1$ & 396 & 25 \\
\hline 11.04 .2013 & 24.04 .2013 & E. imperialis & Tag & $\mathrm{F} 2->\mathrm{N} 2$ & 560 & 13 \\
\hline 22.04 .2013 & 24.04 .2013 & E. imperialis & Tag & $\mathrm{N} 1->\mathrm{N} 2$ & 590 & 2 \\
\hline
\end{tabular}


Table I (continued)

\begin{tabular}{|c|c|c|c|c|c|c|}
\hline Marked & Recaptured & Species & Marker & $\begin{array}{l}\text { Site marked-> } \\
\text { Recaptured }\end{array}$ & $\begin{array}{l}\text { Distance } \\
\text { flown (m) }\end{array}$ & $\begin{array}{l}\text { Days until } \\
\text { recapture }\end{array}$ \\
\hline 22.04 .2013 & 24.04 .2013 & E. imperialis & Tag & $\mathrm{N} 1->\mathrm{N} 2$ & 590 & 2 \\
\hline 22.04 .2013 & 23.04 .2013 & E. imperialis & tag & $\mathrm{N} 1->\mathrm{F} 1$ & 676 & 1 \\
\hline 23.04 .2013 & 27.04 .2013 & E. imperialis & Tag & $\mathrm{F} 1->\mathrm{F} 2$ & 396 & 4 \\
\hline 23.04 .2013 & 04.05 .2013 & E. imperialis & Tag & $\mathrm{F} 1->\mathrm{F} 2$ & 396 & 11 \\
\hline 23.04 .2013 & 27.04 .2013 & E. imperialis & Tag & $\mathrm{F} 1->\mathrm{F} 2$ & 396 & 4 \\
\hline 23.04 .2013 & 04.05 .2013 & E. imperialis & Tag & $\mathrm{F} 1->\mathrm{F} 2$ & 396 & 11 \\
\hline 23.04 .2013 & 24.04 .2013 & E. imperialis & Tag & $\mathrm{F} 1->\mathrm{N} 2$ & 810 & 1 \\
\hline 24.04 .2013 & 07.05 .2013 & E. imperialis & Tag & $\mathrm{N} 2->\mathrm{N} 2$ & 0 & 13 \\
\hline 24.04 .2013 & 04.05 .2013 & E. imperialis & Tag & $\mathrm{N} 2->\mathrm{F} 2$ & 560 & 10 \\
\hline 24.04 .2013 & 05.05 .2013 & E. imperialis & Tag & $\mathrm{N} 2->\mathrm{N} 1$ & 590 & 11 \\
\hline 27.04 .2013 & 04.05 .2013 & E. imperialis & Tag & $\mathrm{F} 2->\mathrm{F} 2$ & 0 & 7 \\
\hline 27.04 .2013 & 04.05 .2013 & E. imperialis & Tag & $\mathrm{F} 2->\mathrm{F} 2$ & 0 & 7 \\
\hline 27.04 .2013 & 06.05 .2013 & E. flammea & $\operatorname{tag}$ & $\mathrm{F} 2->\mathrm{F} 1$ & 396 & 9 \\
\hline 27.04 .2013 & 06.05 .2013 & E. flammea & Tag & $\mathrm{F} 2->\mathrm{F} 1$ & 396 & 9 \\
\hline 04.05 .2013 & 06.05 .2013 & E. flammea & Tag & $\mathrm{F} 2->\mathrm{F} 1$ & 396 & 2 \\
\hline 04.05 .2013 & 06.05 .2013 & E. tridentata & Scratch & $\mathrm{F} 2->\mathrm{F} 1$ & 396 & 2 \\
\hline 04.05 .2013 & 05.05 .2013 & E. flammea & Tag & $\mathrm{F} 2->\mathrm{N} 1$ & 753 & 1 \\
\hline 04.05 .2013 & 05.05 .2013 & E. tridentata & Scratch & $\mathrm{F} 2->\mathrm{N} 1$ & 753 & 1 \\
\hline 04.05 .2013 & 05.05 .2013 & E. villosiventris & Scratch & $\mathrm{F} 2->\mathrm{N} 1$ & 753 & 1 \\
\hline 05.05 .2013 & 06.05 .2013 & E. gorgonensis & scratch & $\mathrm{N} 1->\mathrm{F} 1$ & 676 & 1 \\
\hline 05.05 .2013 & 06.05 .2013 & E. imperialis & Tag & $\mathrm{N} 1->\mathrm{F} 1$ & 676 & 1 \\
\hline
\end{tabular}

establishment of the display territory, they could potentially cover large distances during their life. This is assumed to be essential for the scattered individuals of perfume flower plants, amongst them $>600$ orchid species (Dodson, unpublished data, cited in Williams and Dodson 1972), which depend on the male bees for pollination. Here, we addressed two aspects of the dispersal ability of male euglossine bees, potential obstacles to dispersal and possible flight ranges, using mark and recapture setups.

The recapture rates for the 2262 marked bees in the natural obstacle experiment were below $10 \%$ for each of the marked species, in some species (e.g. E. dodsoni ) even notably lower. Similar recapture rates were reported for males of some euglossine species in Brazil (Tonhasca et al. 2003) and Panama (Ackerman and Montalvo 1985), and it was found that recapture rates for E. imperialis varied between five and $17.5 \%$, depending on the distance between the marking and the recapture site (Kroodsma 1975). Eltz et al. (1999) reported recapture rates as high as $20 \%$ for E. cognata and E. meriana, though these high rates might in part be due to the species studied (higher recapture rates were reported for larger bodied bees, Ackerman and Montalvo 1985) and the restricted area of the experimental site, Barro Colorado Island.

Though there was a notable difference of overall recapture rates between the two marking procedures employed, tags and scratch marks (6 and $1.3 \%$, respectively), this might not be due to differences in the marking procedures or the bees' reactions to them. Scratch marks on caged bees did not seem to alter bee behaviour in any way, and even though tag marked bees in cage settings would spend long time spans trying to remove the tag from their thorax during the first days, this behaviour lessened over time (T. Pokorny, pers. 


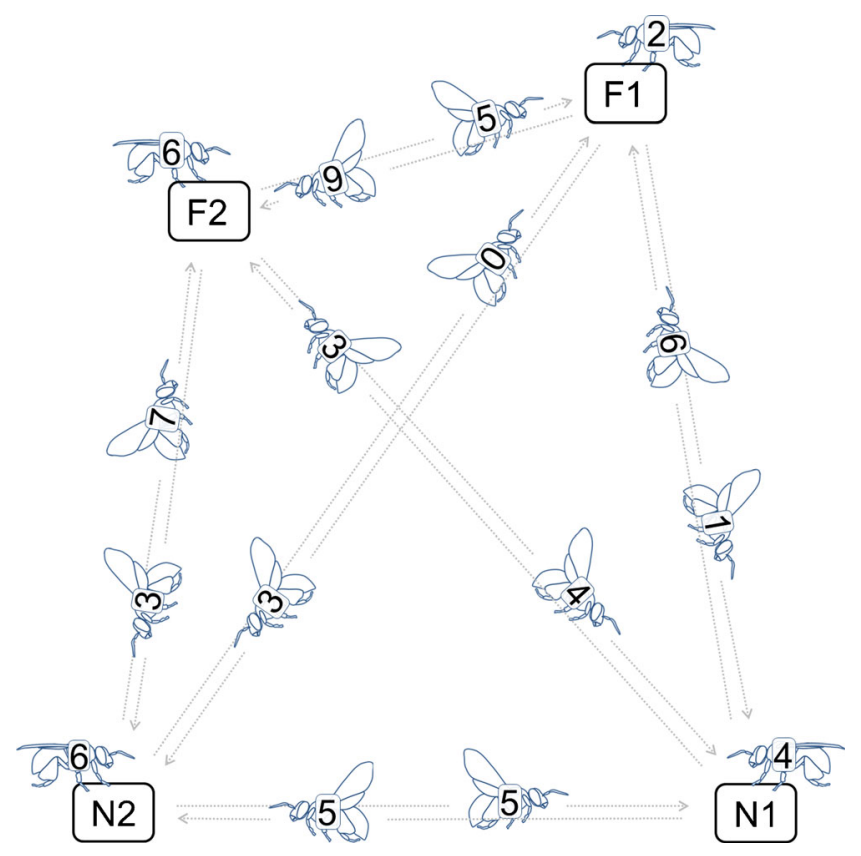

Figure 3. Flight vectors observed in the natural obstacle experiment, including the numbers of bees which had changed between sites and those which had remained at the same site.

obs.). The majority of tag marked recaptures were E. imperialis (32 individuals, $76 \%$ of tag marked recaptures), which in other studies had also been recaptured in high percentages (Kroodsma 1975, and see Ackerman and Montalvo 1985). When bees of this species were exempted, overall recapture rates for both marking procedures were quite similar (1.4\% for tags and $1.3 \%$ for scratch marks), supporting the idea that not the marking type, but the extraordinarily numerous recaptures of tagged E. imperialis led to the differing recapture rates.

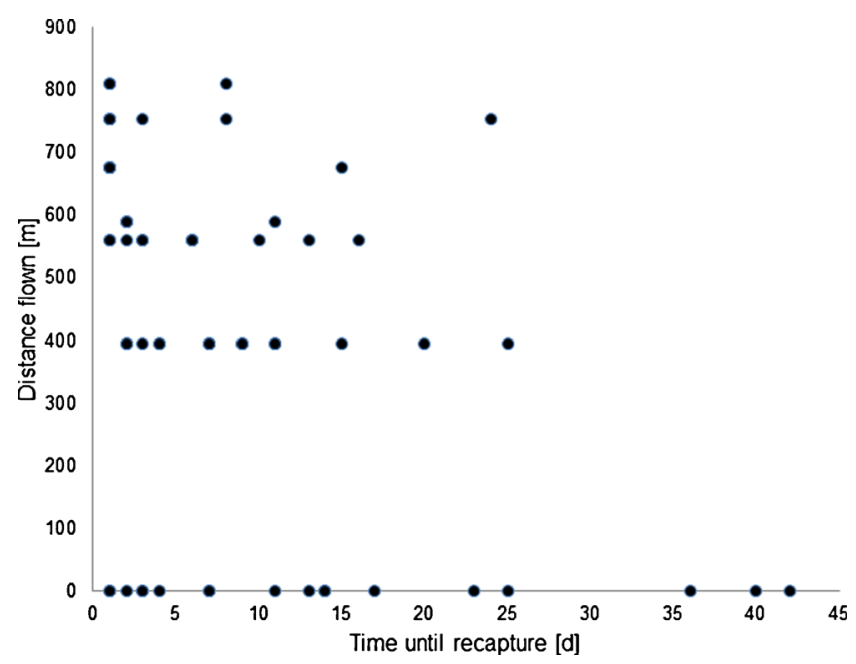

Figure 4. Negative relationship between the times until recapture and the corresponding distances flown by recaptured orchid bees. Spearman rank correlation, $R=-0.45, P<0.01$. 


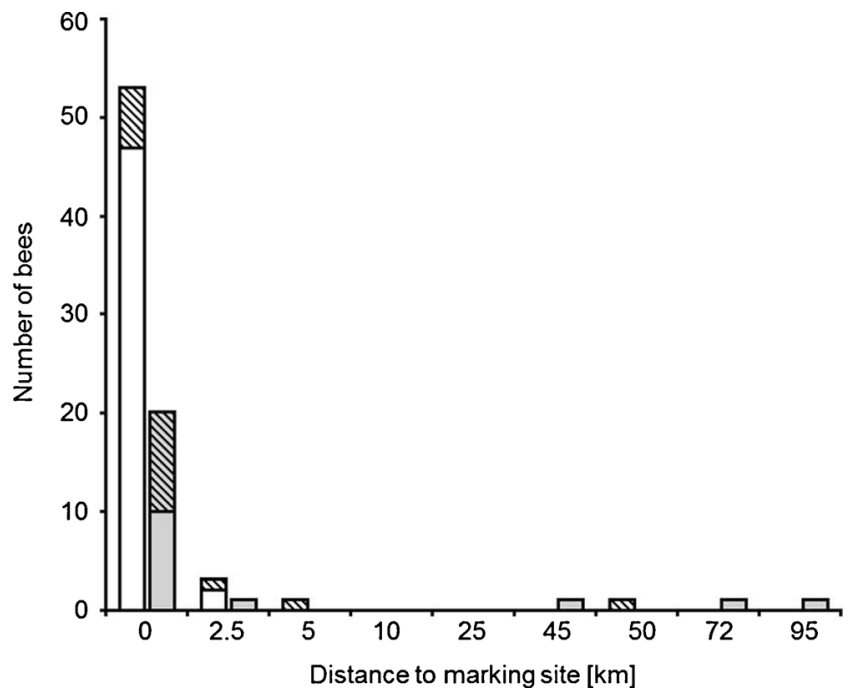

Figure 5. Distances flown by male E. dilemma (white columns) and E. viridissima (grey columns) on the Yucatán peninsula. Clear column parts indicate bees marked with scratch marks, hatched parts indicate bees with chemical marker in their hind leg bouquet. The distances of 72 and $95 \mathrm{~km}$ were flown by two E. viridissima, recaptured at San Crisanto after conclusion of the actual experiment.

Some bees appeared to be residents at specific sites, being recaptured at the same site at which they had been marked. However, the numbers did not differ from those expected if recapture sites were random, suggesting that if home ranges were present, they covered the entire area around the studied sites. The movement patterns as deduced from the flight vectors of recaptured individuals did not seem to be influenced by the moderate natural obstacle chosen in this study, as the bees had moved freely between the sites. Two of three E. imperialis recaptured a second time had
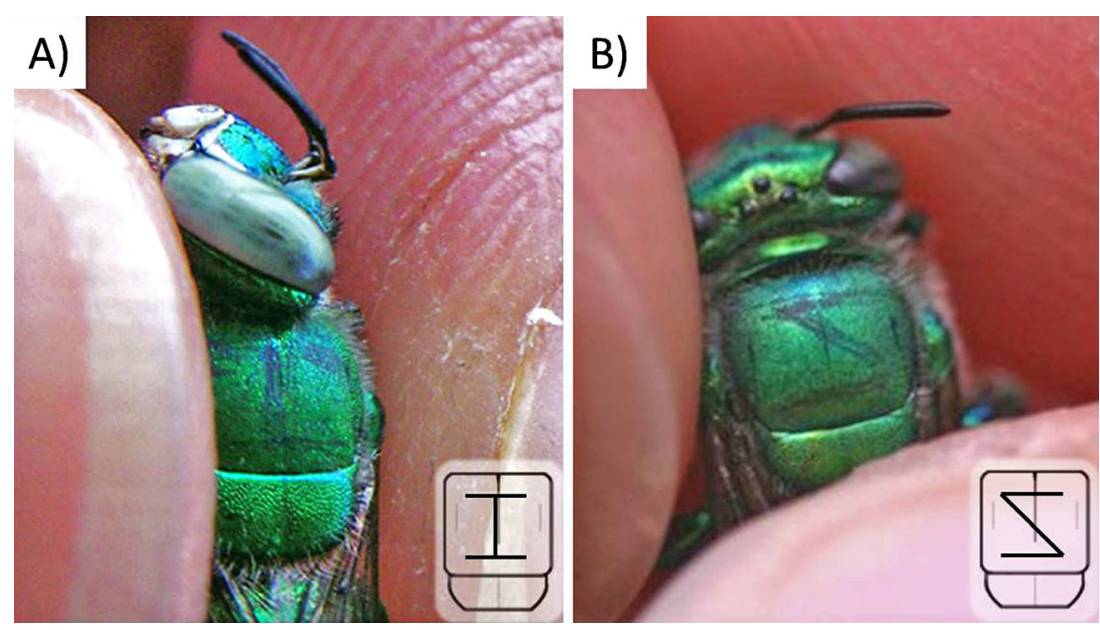

Figure 6. Male bees recaptured after long-distance flights at San Crisanto. Site-specific markings found on the bees' thorax pictured clearer in the lower right corners. a E. viridissima recaptured on April 18, 2012 bearing the mark applied on April 04, 2012 at site B. The distance flown between marking and recapture site was $72 \mathrm{~km}$ within 14 days. b E. viridissima marked at site E on April 08, 2012, recaptured at San Crisanto on April 20, 2012, leading to a traversed distance of $95 \mathrm{~km}$ within 12 days. 
changed their positions between three of the four baiting sites, corroborating this idea. Additionally, some marked bees were sighted near the field station in the valley, again strengthening the view that the animals move freely across and beyond the natural 'obstacle'. In a study involving open pasture between forest fragments and hills, similar results were obtained by Tonhasca et al. (2003), where bees crossed the open pasture across up to $1700 \mathrm{~m}$, with a steep hill not preventing them from locating and visiting volatile baits beyond it. This suggests that moderate natural obstacles do not influence orchid bee movements, and that only more extreme obstacles might function as barriers to orchid bee dispersal. Restrictions on orchid bee movements might, however, not only depend on the size of the obstacle (height of hill/ depth of valley, stretch across open water, area of anthropogenic altered landscape), but also on the species of orchid bee. Some species are more common at forest edges or disturbed sites (e.g. Eulaema nigrita, D. W. Roubik, pers. comm.) and might therefore be less restricted by altered landscape than other species, and larger bees might more easily traverse areas of varying altitudes (see Roubik and Hanson 2004). Analyses on genetic differentiation between mainland and island populations of four euglossine species suggest that even though the stretch of open water does not seem to present an obstacle to three of the species, it did impede the dispersal of one species (Rocha Filho et al. 2013).

The results concerning the time until recapture are similar to those obtained by Eltz et al. (1999), where individual bees were sighted after up to 44 days. Interestingly, we found a negative correlation between travelled distance and time until recapture. Half of the bees recaptured after long time spans (i.e. more than 10 days) were at their original marking site. A possible explanation for this finding is that bees return to sites of chemical resources when some time has passed following initial collection. Orchid bees have been shown to avoid previously collected compounds, and it has been argued that the attraction to the compounds in question might be reformed after a period of time, allowing for the accumulation of the species specific perfume bouquet (Eltz et al. 2005; Pokorny et al. 2013). Such revisiting of sites would not necessarily have to be guided by olfactory cues, but could also be based on visual memory, as suggested for foraging sites (Janzen 1971; Ackerman et al. 1982) and male bees have been observed approaching a fragrance source, Dalechampia spathulata, even after the fragrant flowers had been shed (Armbruster and Webster 1979). The revisiting could be in random order guided by an internal 'map', but it also can be imagined that male orchid bees trapline along a route of different volatile sources covering a large area over long time spans, in a similar fashion as has been postulated on a smaller scale for foraging female bees (Janzen 1971). Trapline foraging is used by many animals visiting renewable patchy resources, particularly by central-place foragers, e.g. foragers that have a fixed starting site, i.e. their nest or burrow. The trapline can be modified upon finding of new, suitable resources (see Lihoreau et al. 2010). The male orchid bee fragrance collecting behaviour is, however, a special case, and differs from food resource visitation in crucial ways. (1) Males are, during most of their lives, potentially not bound to a central place, and even though they may return to a specific sleeping site for a time (see Silva et al. 2011), they probably could use changing places where to spend their nights. (2) Many known euglossine fragrance sources are relatively short lived, potentially widely separated and highly unpredictable in space and time. Perfume flowers as well as non-floral sources may be attractive/available for only one or a few days at a time (many orchids, Araceae, tree wounds, funghi and faeces). Though these points speak against traplining, optimizing a regular route along resources (including nectar plants) might play a role for males that have established a display territory and thus remain in one area. It is assumed that orchid bee males collect fragrances during their entire life, and it might be beneficial for male bees to regularly revisit previous fragrance resources on the chance that they replenish in order to stock up their perfume. Further studies tracking individual male bees over a number of days might help to elucidate this aspect.

Overall, our findings are compatible with the results of Wikelski et al. (2010), who used radio telemetry to monitor the movements of 12 
Exaerete frontalis males for $5 \pm 1.9$ days on Barro Colorado Island. Their data revealed that most males had moved within a home range covering on average $45 \pm 40$ ha during that time, though one individual had travelled $5 \mathrm{~km}$ beyond that. Further studies on this subject would be desirable. They might help to answer questions like whether home ranges are established during a certain point in the bees' lifetime (e.g. when establishing their territory for display), or whether only a number of bees remain as residents in an area, while other bees might choose to (temporarily or entirely) move to another area.

That at least some males do indeed travel far during their lifetime is clearly shown by the results of the experiment on long-range movements conducted on the Yucatán peninsula. The four bees recaptured at 45, 50, 72, and $95 \mathrm{~km}$ from their marking sites represent direct evidence for long distance dispersal in orchid bees, thereby increasing verified euglossine flight ranges by more than an order of magnitude. That four bees were recaptured at such distances despite the relatively low odds given the large areas involved was probably favoured by the circumstances that (1) The Yucatán peninsula is characterized by a patchwork of deciduous secondary forests and shrubs, settlements and farmland (see Hartter et al. 2008), with the habitats around the baiting sites and flanking our $50 \mathrm{~km}$ transect certainly being of aboveaverage quality. This potentially channelled the long-range migrants to our baiting stations. (2) The coastal forest around San Crisanto, where the two most extreme recaptures (both E. viridissima) were made, is a narrow stretch of suitable habitat bordered by the ocean in the north, thus potentially trapping immigrant bees in a relatively small area. (3) The mangroves around San Crisanto appear to be high-quality habitat for orchid bees, supporting high numbers of individuals, as previous baiting experiments have shown (J. Ramirez-Pech pers. comm.; T. Eltz, T. Pokorny pers. obs.). Additionally, they supply rare sources for the major perfume component of this species, a lactone derivative of linolenic acid, which was significantly more common in extracts of hind tibial bouquets from E. viridissima baited at this and other coastal sites (Pokorny et al. 2013). Long-range flights are also congruent with the population genetic structure of E. dilemma. For this species, Zimmermann et al. (2011) found very high overall allelic diversity in the genetic markers used, indicating large population size, but almost no spatial structure within the Yucatán peninsula, suggesting that dispersal is substantial in the absence of geographic or ecological barriers. Studies on euglossine nesting biology have shown that a number of female bees are philopatric in some species (e.g. Augusto and Garófalo 2004; Andrade-Silva and Nascimento 2012), and as females generally are bound to their nesting sites, it seems likely that most of the observed gene flow was due to male dispersal.

We should like to emphasize that extremely long range dispersal as observed in Yucatán may not be commonplace in other geographic regions. The Yucatán peninsula is rather unusual for an orchid bee habitat in several respects. First, it is characterized by an extraordinarily flat topography, which is essentially unparalleled by any other region in the Neotropics. Besides the lack of natural obstacles, dispersal is likely facilitated by the interconnectedness of suitable areas providing sufficient nectar resources, due to the patchy arrangement of secondary forest and interspersed agricultural areas (Hartter et al. 2008). Additionally, the Yucatán peninsula is drier and more seasonal than most euglossine habitats, resulting in low-stature, predominantly deciduous vegetation. This habitat is likely suboptimal regarding the supply of chemical sources for male orchid bees, and may effectively force them to cover larger distances than their counterparts from more humid tropical rainforests (see Janzen 1981).

It remains to be investigated whether all or only a part of the male population travels long distances, and whether long range migrations are undertaken only during a certain stage of life. It has been a long-standing question in euglossine biology whether males are vagabonds or whether they maintain home ranges in which most of the foraging occurs (see Ackerman et al. 1982). Previous marking and radio-tracking studies (Kroodsma 1975; Eltz et al. 1999; Wikelski et al. 2010) are in favour of home ranges, and a certain degree of site fidelity is also expected from the pre-mating behaviour of male orchid bees. For this, males are known to occupy and defend small 
non-resource based territories in the forest understory, showing characteristic series of display for days and even weeks on end. Clearly, this behaviour is at odds with a true vagabond life style. Such a residential phase in the life of a male may nevertheless be preceded by a migratory phase which serves the purpose of seeking and harvesting the various chemicals needed for compilation of the species-specific perfumes. If so, such a biphasic life-style has certain predictions that could be tested in future field studies.

Though the long flight distances traversed by male bees would be beneficial for the stability of euglossine populations also in fragmented habitats (as opposed to the rather interconnected areas underlying this study), this finding should be viewed with caution. As discussed for obstacles, different species may be more or less capable of crossing between forest fragments. Additionally, especially females that will be bound to their nesting site and depend on sufficient nectar and pollen resources to sustain not only themselves but also the provisioning of brood cells might be less inclined to cross over inhospitable terrain on the chance of eventually reaching suitable habitat. Such restrictions might be of less impact if forest fragments are interconnected by corridors or patches of suitable or at least nectar-providing habitat, which could encourage movements of orchid bees and other pollinators along them. Landscape structures in agricultural areas have been shown to influence bumblebee flight paths, and lead to increased seed set in plant patches that were in this way interconnected (Cranmer et al. 2012).

Finally, our data further emphasizes the outstanding role of euglossine bees as longdistance pollinators, especially for Neotropical orchids which regularly occur at low population densities (see Ackerman 1986). Few if any other insects have the potential to regularly carry pollen over dozens of kilometres, but in euglossine bees, such distances have now become more plausible based on our observations. This possibility raises subsequent questions with regard to orchid population biology. If bees do carry orchid pollinaria across regions, then such rare cases of gene flow should leave their mark on orchid population genetics.

\section{ACKNOWLEDGMENTS}

M. Hannibal, N. Blumreiter, I. Vogler, L. Roßmannek, H. Hausmann, J. Henske, C. Castillo, A. Durán Yáñez and R. Guillermo helped with bee capture and marking. Funding was provided by the German Science Foundation (EL249/6) and the PROALMEX program (120989) of the German Academic Exchange Service and the Consejo Nacional de Ciencia y Tecnología (103341) to T.E. and J.Q.E. We want to thank two anonymous reviewers for contributing to improve the manuscript.

Capacité de dispersion des mâles d'abeilles à orchidée et preuve directe de vols de longue distance

Euglossine / pollinisation / orchidée / flux génique / génétique des populations / déplacement longue distance

Ausbreitungspotential männlicher Prachtbienen und direkte Belege für Flüge über große Entfernungen

Euglossini / Orchideenbestäubung / weite Ausbreitungsdistanz / Genfluss / Populationsgenetik

\section{REFERENCES}

Ackerman, J.D. (1983) Diversity and seasonality of male euglossine bees (Hymenoptera: Apidae) in Central Panamá. Ecology 64, 274-283

Ackerman, J.D. (1986) Coping with the epiphytic existence: pollination strategies. Selbyana 9, 52-60

Ackerman, J.D. (1989) Geographic and seasonal variation in fragrance choices and preferences of male euglossine bees. Biotropica 21, 340-347

Ackerman, J.D., Montalvo, A.M. (1985) Longevity of euglossine bees. Biotropica 17, 79-81

Ackerman, J.D., Mesler, M.R., Lu, K.L., Montalvo, A.M. (1982) Food-foraging behavior of male euglossini (Hymenoptera: Apidae): vagabonds or trapliners? Biotropica 14, 241-248

Andrade-Silva, A.C.R., Nascimento, F.S. (2012) Multifemale nests and social behavior in Euglossa melanotricha (Hymenoptera, Apidae, Euglossini). J. Hymenoptera Res. 26, 1-16

Armbruster, W.S., Webster, G.L. (1979) Pollination of two species of Dalechampia (Euphorbiaceae) in Mexico by euglossine bees. Biotropica 11, 278-283

Augusto, S.C., Garófalo, C.A. (2004) Nesting biology and social structure of Euglossa (Euglossa) townsendi Cockerell (Hymenoptera, Apidae, Euglossini). Insectes Soc. 51 , 400-409 
Cappellari, S.C., Harter-Marques, B. (2010) First report of scent collection by male orchid bees (Hymenoptera: Apidae: Euglossini) from terrestrial mushrooms. J. Kansas Entomol. Soc. 83, 264-266

Cranmer, L., McCollin, D., Ollerton, J. (2012) Landscape structure influences pollinator movements and directly affects plant reproductive success. Oikos 121, 562-568

Dodson, C.H., Hills, H.G., Adams, R.M., Williams, N.H. (1969) Biologically active compounds in orchid fragrances. Science 164, 1243-1249

Dressler, R.L. (1968) Observations on orchids and euglossine bees in Panama and Costa Rica. Rev. Biol. Trop. 15, 143-183

Dressler, R.L. (1982) Biology of the orchid bees (Euglossini). Annu. Rev. Ecol. Syst. 13, 373-394

Eltz, T., Whitten, M.W., Roubik, D.W., Linsenmair, K.E. (1999) Fragrance collection, storage and accumulation by individual male orchid bees. J. Chem. Ecol. 25, 157-176

Eltz, T., Roubik, D.W., Lunau, K. (2005) Experiencedependent choices ensure species-specific fragrance accumulation in male orchid bees. Behav. Ecol. Sociobiol. 59, 149-156

Eltz, T., Zimmermann, Y., Pfeiffer, C., Ramirez Pech, J., Twele, R., Francke, W., Quezada-Euan, J.J.G., Lunau, K. (2008) An olfactory shift is associated with male perfume differentiation and species divergence in orchid bees. Curr. Biol. 18, 1844-1848

Hartter, J., Lucas, C., Gaughan, A.E., Aranda, L.L. (2008) Detecting tropical dry forest succession in a shifting cultivation mosaic of the Yucatán peninsula, Mexico. Appl. Geogr. 28, 134-149

Janzen, D.H. (1971) Euglossine bees as long-distance pollinators of tropical plants. Science 171, 203-205

Janzen, D.H. (1981) Bee arrival at two Costa Rican female Catasetum orchid inflorescences, and a hypothesis on euglossine population structure. Oikos 36, 177-183

Kimsey, L.S. (1984) The behavioural and structural aspects of grooming and related activities in euglossine bees (Hymenoptera: Apidae). J. Zool. 204, 541-550

Kroodsma, D.E. (1975) Flight distances of male euglossine bees in orchid pollination. Biotropica 7, 71-72

Lihoreau, M., Chittka, L., Raine, N.E. (2010) Travel optimization by foraging bumblebees through readjustments of traplines after discovery of new feeding locations. Am. Nat. 176, 744-757

Pokorny, T., Hannibal, M., Quezada-Euan, J.J.G., Hedenström, E., Sjöberg, N., Bång, J., Eltz, T. (2013) Acquisition of species-specific perfume blends: influence of habitat-dependent compound availability on odour choices of male orchid bees (Euglossa spp.). Oecologia 172, 417-425
R Core Team (2013) R: A language and environment for statistical computing. R Foundation for Statistical Computing, Vienna, Austria. URL http:/www.Rproject.org/

Raw, A. (1989) The dispersal of euglossine bees between isolated patches of eastern Brazilian wet forest (Hymenoptera, Apidae). Rev. Bras. Entomol. 33, 103-107

Rocha Filho, L.C., Cerântola, N.C.M., Garófalo, C.A., Imperatriz-Fonseca, V.L., Lama, M.A. (2013) Genetic differentiation of the Euglossini (Hymenoptera, Apidae) populations on a mainland coastal plain and an island in southeastern Brazil. Genetica 141, 65-74

Roubik, D. W., Hanson, P. E. (2004) Orchid bees of tropical America. Instituto Nacional de Biodiversidad (INBio)

Silva, M.D., Andrade-Silva, A.C.R., Silva, M. (2011) Long-term male aggregations of Euglossa melanotricha Moure (Hymenoptera: Apidae) on fern fronds Serpocaulon triseriale (Pteridophyta: Polypodiaceae). Neotrop. Entomol. 40, 548-552

Skov, C., Wiley, J. (2005) Establishment of the neotropical orchid bee Euglossa viridissima (Hymenoptera: Apidae) in Florida. Fla. Entomol. 88, 225-227

Tonhasca, A.J., Albuquerque, G.S., Blackmer, J.L. (2003) Dispersal of euglossine bees between fragments of the Brazilian Atlantic Forest. J. Trop. Ecol. 19, 99-102

Vogel, S. (1966) Parfümsammelnde Bienen als Bestäuber von Orchidaceen und Gloxinia . Österr. Bot. Zeitschrift 113, 302-361

Whitten, M.W., Young, A.M., Stern, D.L. (1993) Nonfloral sources of chemicals that attract male euglossine bees (Apidae: Euglossini). J. Chem. Ecol. 19, 3017-3027

Wikelski, M., Moxley, J., Eaton-Mordas, A., López-Uribe, M.M., Holland, R., Moskowitz, D., Roubik, D.W., Kays, R. (2010) Large-range movements of neotropical orchid bees observed via radio telemetry. PLoS ONE 5, e10738

Williams, N.H., Dodson, C.H. (1972) Selective attraction of male euglossine bees to orchid floral fragrances and its importance in long distance pollen flow. Evolution 26, 84-95

Williams, N.H., Whitten, M.W. (1983) Orchid floral fragrances and male euglossine bees: methods and advances in the last sequidecade. Biol. Bull. 164, 355395

Zimmermann, Y., Ramírez, S.R., Eltz, T. (2009) Chemical niche differentiation among sympatric species of orchid bees. Ecology 90, 2994-3008

Zimmermann, Y., Schorkopf, D.L.P., Moritz, R.F.A., Pemberton, R.W., Quezada-Euan, J.J.G., Eltz, T. (2011) Population genetic structure of orchid bees (Euglossini) in anthropogenically altered landscapes. Conserv. Genet. 12, 1183-1194 